children have continued to grow satisfactorily their anatomical bony abnormalities if present, (as in MPS I, II, IV and VI) have not improved after grafting. Thus children with Morquio Disease (MPS IV) (9) and Maroteaux-Lamy Disease (MPS VI) (10) have a disappointing result following BMT, although at first one might have thought they would have been ideal for this treatment, as they have no neurological involvement. There are case reports in the literature of about another thirty inborn errors of metabolism that have been successfully corrected by bone marrow transplantation. (11)

References:

1. Brady RO, Molecular Basis of lysosomal storage diseases, Academic Press Inc 1984, p 461

2. Brady RO, Barranger JA, Gal $A E$ et al Lysosomes and Lysosomal storage diseases, New York, Raven 1980, p 373

3. Gibbs DA, Spellacy E, Thompkins R et al Journal of Inherited Metabolic Diseases 1983, 6:62

4. Adinolfi M, Brown S, Developmental Med and Child Neurol 1984 p 401

5. Hobbs JR, Hugh-Jones K, Shaw PJ et al 1986 Bone Marrow Transplantation Suppl I p 347

6. Shaw PJ, Hugh-Jones K, Hobbs JR et al 1986 Bone Marrow Transplantation Suppl I p 339

7. Shaw PJ, Hugh-Jones K, Hobbs JR et al 1986 Bone Marrow Transplantation Suppl I p 341

8. Shaw PJ, Hugh-Jones K, Hobbs JR et al 1986 Bone Marrow Transplantation Suppl I p 342

9. Desai S, Hobbs JR, Hugh-Jones K et al 1983 Exp Hematol 11 (Suppl 13) p 98

10. Krivit $\mathrm{W}$, Pierpoint ME, Ayak $\mathrm{K}$ et al $\mathrm{N}$ Engl $\mathrm{J}$ Med 1984,311: p 1606

11. Hobbs JR 1985 Plasma Ther Transfus Technol $6: 221$

\section{DNA ANALYSIS AND THE DIAGNOSIS OF INHERITED DISEASE} Robert Williamson

St Mary's Hospital, Medical School, University of London, England

The availability of human DNA sequences in recombinants has transformed human genetics. There are now approximately five hundred coding gene sequences, and innumerable localised anonymous probes, cloned and available pure and in unlimited amount. These can be used by clinical molecular pathologists to study genes in a person-specific way, since any cloned gene sequence is unique to the person from whom it is isolated. Therefore, all of the heritable parameters of individuality, whether representing pathological or normal variation, can be studied by comparing gene sequences.

Many of the cloned human coding genes which have been isolated and characterised to date are also involved in single gene pathology. These include the sequences known to be mutated so as to cause known and characterised Mendelian disorders, such as thalas. saemia, PKU or haemophilia. In such cases, the underlying molecular nature of the defect can be determined, and the probe can be used for population-based carrier testing and for unequivocal prenatal diagnosis. Other common single gene defects of unknown biochemistry, such as cystic fibrosis and Duchenne muscular dystrophy, have been linked either to known DNA coding sequences, or to anonymous DNA probes which are chromosomally localised. In these cases, carrier detection and prenatal (or presymptomatic) diagnosis is only available to informative families with living affected members.

A complete map of the human genome will soon be available, which will simplify the task of determining which gene is mutated and the reason why each causes a characteristic pathology. This is particularly true for those diseases which are locus-heterogeneous, or where more than one gene is involved jointly. Conditions such as coronary artery disease, diabetes and hypertension will be obvious candidates for mapping studies, if accurately diagnosed families of sufficient size are available. For the application of these data, however, it will also be necessary to develop new and inexpensive diagnostic methods for rapid gene analysis using small human tissue samples if these developments are to be applied in communitywide clinical practice.

ONCOGENES AND ANTI-ONCOGENES

Dirk Bootsma

Department of Cell Biology and Genetics, Erasmus University, Rotterdam

At least two classes of genes have been identified, which are important in the pathogenesis of cancer. The first class was originally discovered by the work on acutely transforming RNA tumor viruses and consists of the oncogenes. Activation of these genes by mutation, chromosome translocation or by other means, provides an essential step in the multistage process of malignant transformation. The second class which includes the socalled anti-oncogenes, has been identified in studies of hereditary cancers, in particular Wilms' tumor and retinoblastoma. Whereas oncogenes behave dominantly (one activated copy is sufficient for producing cancer), the antioncogenes show a recessive mode of cancer initiation both alleles have to be inactivated.

An example of the first class is the abelson oncogene (c-abl) which seems to play an essential role in chronic myeloid leukemia (CML). CML is characterized by the presence of the Philadelphia ( $\mathrm{Ph}$ ) chromosome in the leukemic cells of $96 \%$ of all CML patients. The $\mathrm{Ph}^{1}$ chromosome $\left(22 \mathrm{q}^{-}\right)$is the result of a reciprocal translocation between chromosome 22 and chromosome 9, $t$ (9q34,22ql1). Previously we described the localization of the human $c-a b l$ oncogene on chromosome 9 and demonstrated its translocation to the $\mathrm{Ph}^{1}$ chromosome in CML patients (1). The cloning and analysis of breakpoint fragments revealed that the breakpoints on chromosome 22 all cluster in a very limited area, the breakpoint cluster region, bcr (2). Breakpoints on chromosome 9, however, are scattered over a large area. The detection of a chimeric mRNA ( $5^{-} \mathrm{bcr}$ and $3^{-} \mathrm{abl}$ sequences) in the leukemic cells of CML patients $(3,4)$ and the cloning of chimeric cDNAs from a CML derived cell line $\mathrm{K} 562$ $(5,6)$ strongly indicate that bcr and c-abl coding sequences are linked by RNA splicing, independent from the distance between the two genes on the $\mathrm{Ph}^{1}$ chromosome. These findings suggest an important role for the altered $\mathrm{c}-\mathrm{abl}$ product in the generation and/ or maintenance of CML.

Strong evidence for the existence of the second class of genes the socalled anti-oncogenes comes from studies of Wilms' tumor and retinoblastoma. Both tumors seem to be the result of loss or inactivation of the two alleles of a wild type gene located on 11 pl3 in the case of Wilms' tumor (7) and $13 \mathrm{q} 14$ in retinoblastoma (8). In the hereditary form of these tumors the first inactivation event is present in the germ line as a mutation or chromosome deletion, whereas in the non-hereditary cases (mostly unilaterally affected) the first inactivation event occurs in the somatic cell. As a result of a 